Research

\title{
Malaria vector control by indoor residual insecticide spraying on the tropical island of Bioko, Equatorial Guinea Brian L Sharp ${ }^{1}$, Frances C Ridl*1, Dayanandan Govender ${ }^{1}$, Jaime Kuklinski ${ }^{2}$ and Immo Kleinschmidt ${ }^{1}$
}

\author{
Address: ${ }^{1}$ Malaria Research Lead Programme, Medical Research Council, 491 Ridge Rd, Durban, South Africa and ${ }^{2}$ One World Development \\ Group, Gainesville, Florida \\ Email: Brian L Sharp - bsharp@mrc.ac.za; Frances C Ridl* - fridl@mrc.ac.za; Dayanandan Govender - dgovender@mrc.ac.za; \\ Jaime Kuklinski - jaime@owdg.org; Immo Kleinschmidt - ikleinschmidt@mrc.ac.za \\ * Corresponding author
}

Published: 2 May 2007

Malaria Journal 2007, 6:52 doi:10.1186/1475-2875-6-52

This article is available from: http://www.malariajournal.com/content/6/I/52

(c) 2007 Sharp et al; licensee BioMed Central Ltd.

This is an Open Access article distributed under the terms of the Creative Commons Attribution License (http://creativecommons.org/licenses/by/2.0), which permits unrestricted use, distribution, and reproduction in any medium, provided the original work is properly cited.
Received: 3I January 2007

Accepted: 2 May 2007

\begin{abstract}
Background: A comprehensive malaria control intervention was initiated in February 2004 on Bioko Island, Equatorial Guinea. This manuscript reports on the continuous entomological monitoring of the indoor residual spray (IRS) programme during the first two years of its implementation.
\end{abstract}

Methods: Mosquitoes were captured daily using window traps at 16 sentinel sites and analysed for species identification, sporozoite rates and knockdown resistance $(k d r)$ using polymerase chain reaction (PCR) to assess the efficacy of the vector control initiative from December 2003 to December 2005.

Results: A total of 2,807 and 10,293 Anopheles funestus and Anopheles gambiae s.l. respectively were captured throughout the study period. Both $M$ and $S$ molecular forms of An. gambiae s.s. and Anopheles melas were identified. Prior to the first round of IRS, sporozoite rates were 6.0, 8.3 and 4.0 for An. gambiae s.s., An. melas and An. funestus respectively showing An. melas to be an important vector in areas in which it occurred. After the third spray round, no infective mosquitoes were identified. After the first spray round using a pyrethroid spray the number of An. gambiae s.s. were not reduced due to the presence of the $k d r$ gene but An funestus and An. melas populations declined from 23.5 to 3.1 and 5.3 to 0.8 per trap per 100 nights respectively. After the introduction of a carbamate insecticide in the second round, An. gambiae s.s. reduced from 25.5 to 1.9 per trap per 100 nights and An. funestus and An. melas remained at very low levels. Kdr was found only in the Mform of An. gambiae s.s. with the highest frequency at Punta Europa (85\%).

Conclusion: All three vectors that were responsible for malaria transmission before the start of the intervention were successfully controlled once an effective insecticide was used.

Continuous entomological surveillance including resistance monitoring is of critical importance in any IRS based malaria vector control programme. This paper demonstrates that sufficient resources for such monitoring should be included in any proposal in order to avoid programme failures. 


\section{Background}

Malaria is a major endemic disease in the Central African tropical island of Bioko, Equatorial Guinea. High prevalence of infection with malarial parasites in children has been reported $[1,2]$. Anopheles gambiae sensu stricto (s.s.), Anopheles melas and Anopheles funestus are responsible for malaria transmission on the island $[3,4]$ resulting in entomological inoculation rates (EIR) of up to 281 and 787 infective bites per year for An. gambiae s.s. and An. funestus respectively [4].

Bioko has an all year round humid climate with a short dry season from November to March. The population is estimated at 250,000 most of who live in or around Malabo, the capital of Equatorial Guinea.

In February 2004, The Bioko Island Malaria Control Project (BIMCP) initiated a comprehensive malaria control intervention consisting of indoor residual spraying (IRS) and effective case management, funded by a consortium led by Marathon Oil Company in partnership with the government of Equatorial Guinea, Medical Care Development International (MCDI), One World Development Group (OWDG), Medical Research Council of South Africa (MRC) and Harvard University. The intervention was monitored by entomological, clinical and population indicators [2].

This paper reports on the continuous entomological monitoring of the IRS programme during the first two years of its implementation (2004-2005). Monitoring of the impact of the intervention on prevalence of infection in children has previously been reported [2].

\section{Materials and methods Intervention}

The intervention consists of vector control through (IRS) aimed at covering all domicillary structures, and an extensive programme of case management by provision of definitive diagnosis, treatment with artemisinin-based combination therapy, and intermittent preventive treatment (IPT) to pregnant women.

The first round of IRS using the synthetic pyrethoids Deltamethri $^{\mathrm{TM}}$ and Fendona ${ }^{\mathrm{TM}}$ was carried out between March 2004 and August 2004. In 2005, two spray rounds took place, during February-July and August-December respectively, mainly using the carbamate insecticide Ficam ${ }^{\mathrm{TM}}$. Approximately 100,000 houses were sprayed each round.

\section{Entomological monitoring}

Spray operations were similar to those developed in the Lubombo Spatial Development Initiative (LSDI) in Mozambique, Swaziland and South Africa [5]. Progress and performance of spray operations were continually monitored with the use of a computerized spray management system which was adapted from Booman et al. [6].

In November 2003, prior to the implementation of the control programme, window traps were installed at six houses at each of sixteen sentinel sites (Figure 1). Collections were made daily by the trained home owner emptying the contents of the window trap into pre-labeled specimen jars containing isopropanol and completing checklists specifying nights for which traps were operating. The jars were collected and replaced at four week intervals. Mosquitoes were dispatched to the MRC in Durban for morphological identification and molecular analyses.

Mosquitoes were collected prior to the onset of the programme to allow for comparison between pre- and post intervention periods. The number of mosquitoes caught was compared over time, between sentinel sites and with respect to species composition, infection rates and the pattern of pyrethoid knockdown resistance $(k d r)$.

\section{Identification of vector species, sporozoite rates, molecular forms and kdr mutations}

Mosquitoes were separated into Culicinae and Anophelinae and counted. Anophelines were morphologically identi-

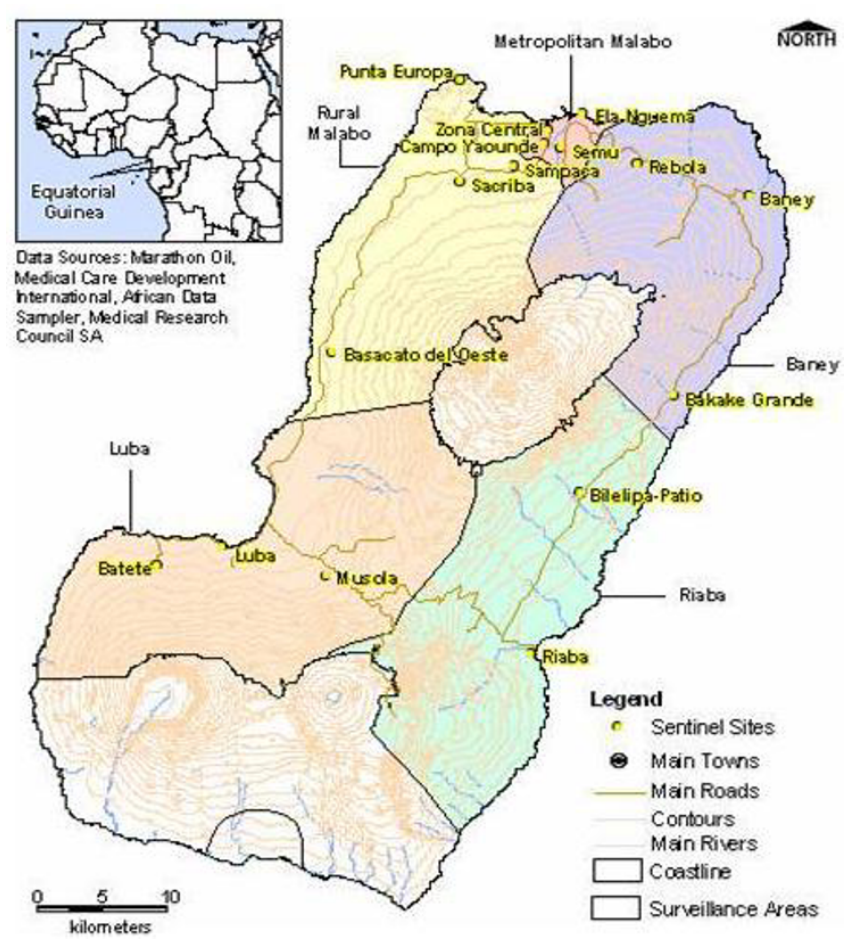

Figure I

Location of window trap sites used to monitor the Bioko Island Malaria Vector Control Programme intervention. 
fied into An. gambiae s.l. and An. funestus using the keys described by Gillies and De Meillon [7] and Gillies and Coetzee [8] and individually stored in isopropanol for subsequent molecular studies.

DNA was extracted from the head and thorax of a subsample of mosquitoes using the Livak method [9]. Members of the An. gambiae complex were identified using the Polymerase Chain Reaction (PCR) method described by Scott et al [10]. Molecular forms within An. gambiae s.s were identified using the protocol of Favia et al. [11] and all negative samples or those showing discrepancies were repeated using the protocol of Fanello et al. [12]. Members of the An. funestus group were identified using PCR as described by Koekemoer et al. [13]. The presence of Plasmodium falciparum sporozoites was determined using the PCR protocol by Snounou et al. [14]. The detection of the west African Leu-Phe $k d r$ mutation was based on the PCR method of Martinez-Torres et al. [15].

Numbers of mosquitoes per trap per night were calculated for each vector species, both pre- and post-IRS, based on day of capture of the specimen in relation to spray status of the site in which the window trap was located. Using the species specific estimated sporozoite prevalence, the number of infective mosquitoes per trap per night, by species was calculated; the ratio of infective numbers per trap per night post spraying, relative to pre-spraying, was defined as the relative transmission index.

All culicenes caught were recorded to ensure that in the absence of anopheline catches, the traps were being successfully operated.

\section{Results \\ Vector species identification}

During this study, which comprised 59,307 trapping nights, 10,293 An. gambiae s.l. and 2,807 An. funestus were collected and morphologically identified. Of these, 2,043 An. gambiae s.l. and 588 An. funestus were subjected to species specific analysis (Table 1). An gambiae s.s. and An. melas were the only two members of the An. gambiae complex and An. funestus was the only member of the $A n$. funestus group to be identified. Prior to spraying An. gambiae s.s. was identified from all sixteen sentinel sites and An. melas from four sites (Basacato del Oeste, Luba, Punta Europa and Riaba). An. funestus was identified from ten sites (Basacato del Oeste, Batete, Ela Nguema, Musola, Punta Europa, Rebola, Riaba, Sacriba, Sampaka and Semu). After the third spray round, An. gambiae s.s. was

Table I: Density, Sporozoite prevalence and Transmission index of specimens collected at sentinel sites in Bioko, 2004-2005

\begin{tabular}{|c|c|c|c|c|}
\hline & Pre spray & Post spray I & Post spray 2 & Post spray 3 \\
\hline \multicolumn{5}{|l|}{ An. gambiae s.l. } \\
\hline No. caught & 2389 & 7427 & 341 & 136 \\
\hline No. analysed for species identification & 719 & 1017 & 230 & 77 \\
\hline Proportion An. gambiae s.s. (\%) & 82 & 97 & 88 & 90 \\
\hline \multicolumn{5}{|l|}{ An. gambiae s.s. } \\
\hline No. estimated & 1959 & 7204 & 300 & 122 \\
\hline No. per trap per 100 nights & 23.9 & 25.5 & 1.9 & 1.7 \\
\hline Sporozoite rate & $6.0(n=586)$ & $1.4(n=985)$ & $0(n=203)$ & $0(n=69)$ \\
\hline Transmission index $\S$ & 1.4 & 0.36 & 0 & 0 \\
\hline Transmission index relative to baseline & I & 0.26 & 0 & 0 \\
\hline \multicolumn{5}{|l|}{ An. melas } \\
\hline No. estimated & 430 & 223 & 41 & 14 \\
\hline No. per trap per 100 nights & 5.3 & 0.8 & 0.3 & 0.2 \\
\hline Sporozoite rate & $8.3(n=133)$ & $3 . I(n=32)$ & $0(n=27)$ & $0(n=8)$ \\
\hline Transmission index§ & 0.44 & 0.03 & 0 & 0 \\
\hline Transmission index relative to baseline & I & 0.07 & 0 & 0 \\
\hline \multicolumn{5}{|l|}{ An. funestus } \\
\hline No. caught & 1920 & 874 & 10 & 3 \\
\hline No. analysed for species identification & 372 & 215 & I & 0 \\
\hline No. per trap per 100 nights & 23.5 & 3.1 & 0.06 & 0.04 \\
\hline Sporozoite rate & $4.0(n=372)$ & $2.3(n=215$ & $0(n=1)$ & $*$ \\
\hline Transmission index $\S$ & 0.94 & 0.07 & $*$ & * \\
\hline Transmission index relative to baseline & I & 0.08 & * & $*$ \\
\hline
\end{tabular}

* Not computed due to insufficient specimens

$\S$ Number of infective mosquitoes per 100 trap nights 
identified from eight sites (Baney, Basacato del Oeste, Bilelipa, Campo Yaounde, Luba, Punta Europa, Rebola and Sacriba) and An. melas only from Punta Europa. No An. funestus were caught in window traps after the third spray round.

An. gambiae s.s. accounted for more than $80 \%$ of the An. gambiae s.l. captured over the duration of the study period and both the $\mathrm{M}$ and the $\mathrm{S}$ molecular forms were identified. An. melas predominated at one site, Riaba, accounting for $94 \%$ of the An. gambiae s.l. identified at this site prior to IRS $(\mathrm{n}=108)$. After the third spray round, no An. melas were identified from this locality.

\section{Mosquito densities, sporozoite rates and transmission index}

The estimated number of An. gambiae s.s. per window trap per 100 nights, pre spraying was $>20$ with $A$. melas markedly lower at $<5$. An. gambiae s.s. showed an increase in the estimated number per window trap post spray round 1 (from 23.9 to 25.5 per trap per 100 nights) but was markedly reduced to two mosquitoes per trap per 100 nights after the second spray round with carbamate insecticide (Table 1). Both An. melas and An. funestus showed significant reductions after the first spray round (from 5.3 to 0.8 and from 23.5 to 3.1 respectively) and continued to drop further with the subsequent spray round (to 0.2 and 0.04 respectively).

Prior to the onset of IRS, large variations in mosquito numbers existed between sentinel sites with densities of An. gambiae s.l. and An. funestus ranging from $<1$ per trap per 100 nights to 182.9 (Punta Europa) and 140.9 (Sacriba) per trap per 100 nights respectively.

Sporozoite prevalence prior to spraying was $6.0 \%, 8.3 \%$, and $4.0 \%$ for An. gambiae s.s., An. melas and An. funestus respectively. After the first spray round with a pyrethoid spray, these reduced to $1.8 \%, 3.1 \%$ and $2.3 \%$ and after the second spray round, no infective mosquitoes were identified (Table 1).

The relative transmission index (the number of infective mosquitoes per trap per night relative to pre-intervention) was 0.26, 0.07, 0.08 for An. gambiae s.s., An. melas and An. funestus respectively after the first spray round. All mos- quitoes tested after the second spray round were negative for sporozoites so no transmission index could be calculated (Table 1).

\section{Culicene densities}

Prior to the onset of IRS, culicene densities were 130.2 per trap per 100 nights. Post spraying, densities were 108.0, 115.6 and 81.4 per trap per 100 nights for each spray round respectively. Large variations in culicene numbers existed between sentinel sites, throughout the study period with densities ranging from 6 to 461 per trap per 100 nights.

\section{$M$ and $S$ molecular forms of An. gambiae s.s. and the relationship to $\mathbf{k d r}$}

Prior to the onset of spraying, 64\% of An. gambiae s.s. were identified as S-forms and $36 \%$ as $M$-forms $(n=362)$. The proportion of $\mathrm{M}$ forms rose steadily with each spray round and by the end of the third spray round, $80 \%$ of An. gambiae s.s. were identified as $M$ forms $(n=63)$. S-forms only were found at Baney, Batete, Bilelipa, Musola and Rebola and $\mathrm{M}$-forms only from Central and Bacake Grande. M and $\mathrm{S}$ forms were sympatric at all other localities. No hybrids were identified.

Prior to the onset of IRS, 50\% of M-forms had either the homozygous resistant $(k d r / k d r)$ or the heterozygous susceptible $(k d r /+) k d r$ genotypes (Table 2$)$. By the end of the third spray round, $78 \%$ of $M$-forms had either one of the $k d r$ genotypes. $K d r$ was absent in all S-forms. The $k d r$ mutation was identified at eight sentinel sites, Basacato del Oeste, Punta Europa, Sampaka, Sacriba, Campo Yaounde, Central and Semu, all of which are in the northwest of the island and Luba in the south-west.

\section{Discussion}

Prior to intervention by IRS, An. gambiae s.s. and An. funestus were shown to be the major malaria vector species biting on the island of Bioko. This corroborates previous reports of the anopheline distribution and their infectivity for the island $[4,16]$. The first round of IRS with a pyrethoid insecticide dramatically reduced the An. funestus and An. melas populations which remained at very low levels following second and third round IRS with a carbamate. The first IRS round with a pyrethoid had no effect on the number of An. gambiae s.s. collected, but did reduce

Table 2: Kdr in M-forms of An. gambiae s.s. collected in Bioko, 2004-2005

\begin{tabular}{lccccc}
\hline & Total number tested & $\begin{array}{c}\text { Number Resistant } \\
(\mathrm{kdr} / \mathrm{kdr})\end{array}$ & $\begin{array}{c}\text { Number Susceptible/ } \\
\text { Resistant }(+/ \mathrm{kdr})\end{array}$ & $\begin{array}{c}\text { Number Susceptible } \\
(+/+)\end{array}$ & $\begin{array}{c}\text { Percent Resistant (R } \\
\text { and SR) }\end{array}$ \\
\hline Pre spray & 105 & 16 & 37 & 52 & 50 \\
Post spray 1 & 132 & 22 & 61 & 49 & 63 \\
Post spray 2 & 102 & 27 & 19 & 33 & 7 \\
Post spray 3 & 30 & 4 & 68 & 78 \\
\hline
\end{tabular}


their sporozoite rate, thereby substantially lowering their transmission potential as expressed by the transmission index. This is likely to be the result of a change in the age structure of An. gambiae s.s. after the first round of spraying with a pyrethoid. It was only after the introduction of a carbamate insecticide that the number of An. gambiae s.s. exiting through window traps were significantly reduced and remained low with subsequent IRS rounds with a carbamate.

An. melas was implicated as an important vector of malaria in localized areas in which it occured. Its distribution was restricted to coastal areas and had the highest infectivity rate of the three species prior to IRS intervention and after the first spray round. The transmission index was however lower due to the low numbers caught. Akogbero et al. [17] found that the infectivity of An. melas in coastal areas of Benin was lower compared to that of An. gambiae s.s. in places where An. melas was most abundant. Morreno et al. [18], found similar infection rates for both An. melas and An. gambiae s.s. in Equatorial Guinea (mainland). The present findings corroborate this study and show that in areas where both vectors cohabit (Punta Europa and Riaba), regardless of which one is dominant, infectivity rates were similar.

The two genetic variants of An. gambiae s.s., the molecular $\mathrm{M}$ form and $\mathrm{S}$ form were both identified throughout the study period. The data indicated a strong selection for the $\mathrm{M}$ form over the IRS intervention period, which is linked to the presence of the $k d r$ mutation.
A study on Bioko between 1998 and 2001 reported no evidence of $k d r$ in the An. gambiae s.s. population despite the use of pyrethoid-impregnated bednets [3]. It was on the basis of this study that the decision was made to implement IRS with a pyrethoid insecticide. However, retrospective analysis of samples collected prior to IRS and analysed in 2004, showed the presence of $k d r$ in $50 \%$ of $\mathrm{M}$-forms tested but absent in the $\mathrm{S}$ form (Table 2). This was confirmed by Reimer et al. [19] who reported the $k d r$ gene present in 55\% of molecular M-forms of An gambiae s.s. from Malabo but absent from the S-form. The frequency of the $k d r$ allele continued to rise and by the end of 2005, was present in $78 \%$ of $\mathrm{M}$-forms, but absent in Sforms and reached a maximum frequency of $85 \%$ at Punta Europa sentinel site. Pyrethroids were mainly withdrawn from use in IRS in 2004 after the first spray round and replaced with a carbamate insecticide. However, pyrethroids were still frequently used in the form of vehicle and hand fogging in Malabo [19]. Some pyrethroids were also used in the IRS programme as late as 2005 constituting $17 \%$ of the total structures sprayed. Thus pyrethroids from fogging, IRS and ITNs were present for selection resulting in the increasing frequency of the $\mathrm{M}$ form of $A n$. gambiae s.s. due to the presence of the $k d r$ gene. Figure 2 shows the continual increase in An. gambiae s.l. caught exiting houses from March 2004 in spite of the implementation of the IRS programme using a pyrethroid. The failure to control An. gambiae s.s. effectively with a pyrethroid due to $k d r$ is demonstrated by the effective reduction in the seasonal peak in An. gambiae s.s. after the introduction of carbamate IRS (Figure 2). In contrast to An. gambiae s.s.

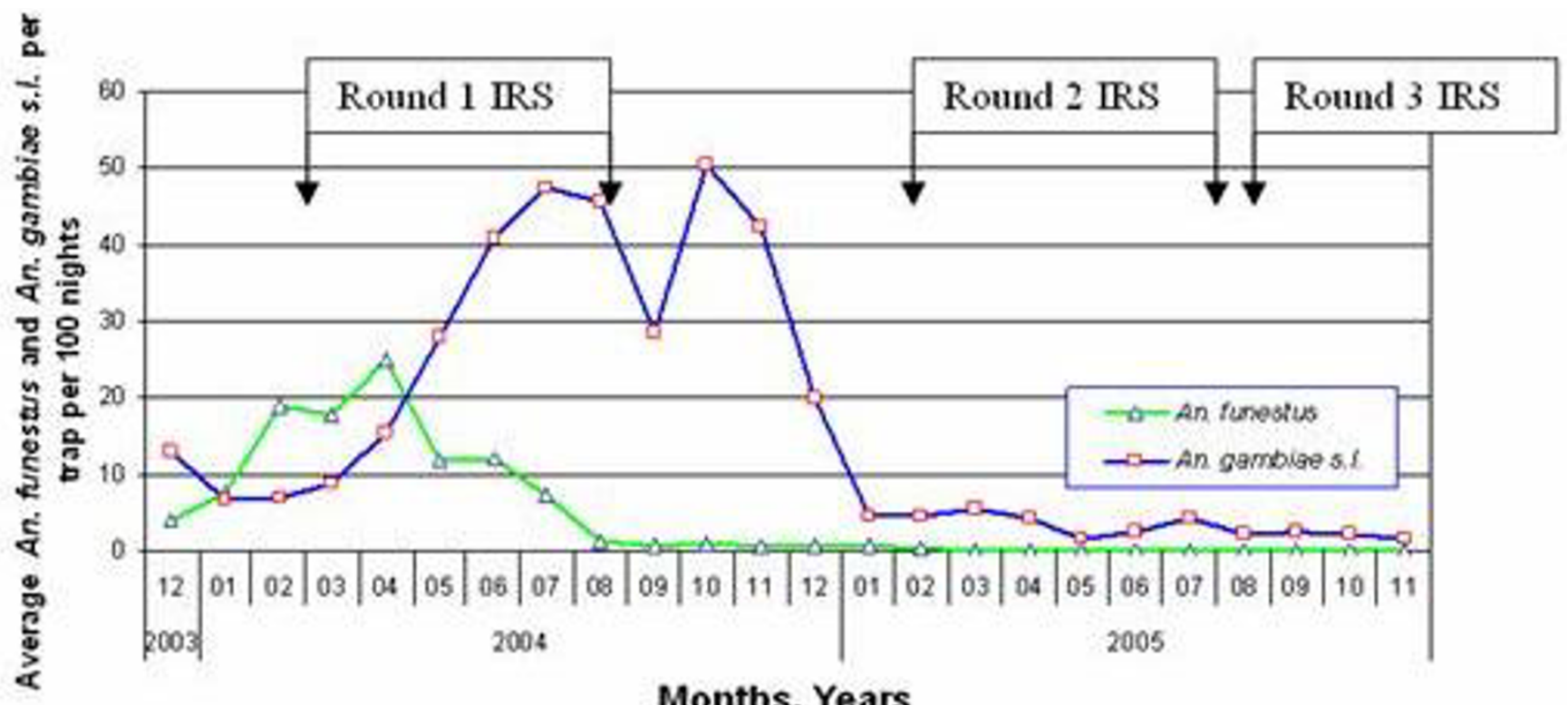

Figure 2

Average number of An. gambiae s.l. and An. funestus per window trap per 100 nights, Bioko, December 2003-November 2005. 
the relative abundance of house leaving An. funestus and An. melas was dramatically reduced following the first round of IRS using a pyrethroid and remained low with the introduction of a carbamate. The efficacy of a carbamate insecticide for large scale IRS was recently also demonstrated in Mozambique for both An. arabiensis and non $k d r$ pyrethroid resistant An. funestus [5].

This study further emphasizes the importance of monitoring and evaluation in any large scale insecticide based vector control programme. The efficacy of the IRS programme in Bioko is demonstrated by the dramatic reduction in An. funestus and An. melas in the first spray round and An. gambiae s.s. by the second spray round, and the substantial decrease in the transmission index after the first year, a finding supported by the significant decrease in the parasite prevalence in children by one third after the first year of IRS [2].

These results lead us to emphasise the critical importance of continuous entomological surveillance including insecticide resistance monitoring based on an extensive system of window traps in any IRS based malaria vector control programme. It is recommended that proposals for such interventions include sufficient resources for such monitoring to avoid programme failures that may result from the ineffective control of important malaria vectors.

\section{Authors' contributions}

BLS: Co-designed the study, participated in analysis and interpretation of data and contributed to the drafting of the manuscript. FCR carried out the laboratory analyses of mosquitoes, assisted with data analysis and interpretation and was involved in the drafting of the manuscript. DG: Managed the database, assisted with the analysis of results and contributed to the manuscript. JK: Management of IRS and the collection of field samples and contributed to the manuscript. IK: Co-designed and coordinated the study, participated in the analysis and interpretation of results, and was involved it the drafting of the manuscript and critical evaluation thereof.

\section{All authors read and approved the manuscript.}

\section{Acknowledgements}

We thank Drs Adel Chanouch, Brian Linder and Susan Rynard from Marathon Oil Company for their constructive involvement in the execution of the BIMCP; Dr. Chris Schwabe from MCDI for his oversight and his critical involvement in the project; Mr Ruben Biebeda from One World Development Group (OWDG) for his efficient management of IRS in the BIMCP. We would also like to thank Dr. Janet Hemingway from the Liverpool School of Tropical Medicine and Hygiene for quality control of $k d r$ specimen analysis and Dr. Michael Coleman for supplying $k d r$ control samples.

\section{References}

I. Roche J, Ayecaba S, Amela C, Alvar J, Benito A: Epidemiological characteristics of malaria in Equatorial Guinea. Res Rev Parasitol 1996, 56:99-104.

2. Kleinschmidt I, Sharp B, Benevente L, Schwabe C, Torrez M, Kuklinski J, Morris N, Raman J, Carter J: Reduction in infection with Plasmodium falciparum one year after the introduction of malaria control interventions on Bioko Island, Equatorial Guinea. Am J Trop Med Hyg 2006, 74:972-978.

3. Berzosa PJ, Cano J, Roche J, Rubia JM, Garcia L, Moyano E, Guerra A, Mateos JC, Petraca V, Do Rosaria V, Benito A: Malaria vectors in Bioko island (Equatorial Guinea): PCR determination of the members of Anopheles gambiae Giles complex (Diptera: Culicidae) and pyrethoid knockdown resistance (kdr) in An. gambiae sensu stricto. J Vector Ecology 2002, 27:102-106.

4. Cano J, Berzosa PJ, Roche J, Rubio JM, Moyano E, Guerra-Neira H, Brochero $H$, Mico M, Edu M, Benito A: Malaria vectors in the Bioko Island (Equatorial Guinea): estimation of vector dynamics and transmission intensities. J Med Entomol 2004, 4I:|58-|6I.

5. Sharp BL, Kleinschmidt I, Streat E, Maharaj R, Barnes KI, Durrheim DN, Ridl FC, Morris N, Seocharan I, Kunene S, La Grange JJP, Mthembu DJ, Maartens F, Martin CL, Barreto A: Seven years of regional malaria control collaboration-Mozambique, South Africa and Swaziland. Am J Trop Med Hyg 2007, 76:42-47.

6. Booman M, Sharp BL, Martin CL, Manjate B, La Granga K, Durheim DN: Enhancing malaria controlusing a computerized management system in Southern Africa. Malar J 2003, 2:I3.

7. Gillies MT, De Meillon B: The Anophelinae of Africa south of the Sahara Publication of the South African Institute for Medical Research, Johannesburg; 1968:54.

8. Gillies MT, Coetzee M: A Supplement to the Anophelinae of Africa South of the Sahara (Afrotropical Region) Publication of the South African Institute for Medical Research, Johannesburg; 1987:55.

9. Collins FH, Mendez MZ, Rasmussen MO, Mehaffey PC, Bensansky NJ, Finnerty $V$ : A ribosomal RNA gene probe differentiates member species of the Anopheles gambiae complex. Am J Trop Med Hyg 1987, 37:37-4I.

10. Scott JA, Brogdon WG, Collins FH: Identification of single specimens of the Anopheles gambiae group by polymerase chain reaction. Am J Trop Med Hyg 1993, 49:520-529.

II. Favia G, Lanfracotti A, Spanos L, Siden-Kiamos, Louis C: Molecular characterization of ribosomal DNA polymorphisms discriminating among chromosomal forms of Anopheles gambiae s.s. Insect Mol Biol 200I, I 0:19-23.

12. Fanello C, Santolamazza F, della Torre A: Simultaneous identification of species and molecular forms of the Anopheles gambiae complex by PCR-RFLP. Med Vet Entomol 2002, I 6:46 I-464.

13. Koekemoer LL, Kamau L, Hunt RH, Coetzee M: A cocktail polymerase chain reaction assay to identify members of the Anopheles funestus (Diptera: Culicidae) group. Am J Trop Med Hyg 2002, 6:804-8II.

14. Snounou G, Viriyakosol S, Zhu XP, Jarra W, Pinheiro L, do Rosario $\mathrm{VE}$, Thaithong S, Brown KN: High sensitivity of detection of human malaria parasites by the use of nested polymerase chain reaction. Mol Biochem Parasitol 1993, 6 I:3 I5-320.

15. Martinez-Torres D, Chandre F, Williamson MS, Darriet F, Berge JB, Devenshire AL, Guillet P, Pasteur N, Pauron D: Molecular characterization of pyrethoid knockdown resistance (kdr) in the major malaria vector Anopheles gambiae s.s. Insect $\mathrm{Mol}$ Bio 1998, 7:179-184.

16. Molina R, Benito A, Roche J, Blanca F, Amele C, Sanchez A, Alvar J: Baseline entomological data for a pilot malaria control programme in Equatorial Guinea. J Med Entomol 1993, 3:622-624.

17. Akogbero M, Romano R: Infectivity of Anopheles melas vis-à-vis Plasmodium falciparum in the coastal lagoon area of Benin. Bull Soc Pathol Exot 1999, 92:57-6I.

18. Moreno M, Cano J, Nzambo S, Bobuakasi L, Buatiche JN, Ondo M, Micha F, Benito A: Malaria Panel assay vs PCR: detection of naturally infected Anopheles melas in a coastal village of Equatorial Guinea. Malar J 2004, 3:20.

19. Reimer LJ, Tripet F, Slotman M, Spielman A, Fonjo E, Lanzaro GC: An unusual distribution of the $k d r$ gene among populations of Anopheles gambiae on the island of Bioko, Equatorial Guinea. Insect Mol Biol 2005, 14:683-688. 